\title{
Food Stamp and School Lunch Programs Alleviate Food Insecurity in Rural America
}

\author{
KRISTIN SMITH AND SARAH SAVAGE
}

I n 2004, 13 percent of American rural households were "food insecure," meaning that at some point during the year they did not have access to enough food for all household members, and 4 percent of rural households experienced hunger. ${ }^{1}$ The Food Stamp and the National School Lunch programs play a vital role in helping poor, rural Americans obtain a more nutritious diet and alleviate food insecurity and hunger.

Congress is currently debating the 2007 Farm Bill. One of the provisions in that bill addresses domestic food and nutrition assistance and includes reauthorization of the Food Stamp Program and the Fresh Fruits and Vegetables Program, among others. The Food Stamp Program is a central component of the nation's policy to alleviate hunger and poverty and helps low-income families and individuals purchase a nutritionally adequate diet. The Fresh Fruits and Vegetables Program distributes fresh fruits and vegetables to elementary, middle, and high school children in participating schools, and is administered by each state's National School Lunch and Breakfast Programs, which are funded under the Child Nutrition Act.

This fact sheet looks at the extent to which rural America depends on food stamps and free or reduced price lunches, and describes characteristics of beneficiaries of these federal nutrition assistance programs.

\section{Rural Americans Rely on Food Stamps}

Rural Americans disproportionately rely on the Food Stamp Program to help purchase food for a healthy diet. The Current Population Survey (CPS) shows that 16 percent of the nation's population lived in a nonmetropolitan, or rural, area in 2006, yet 21 percent of food stamp beneficiaries lived there. ${ }^{2}$ Overall, 10 percent of America's rural population relied on food stamps, compared with 7 percent of urban residents (see Table 1).
Children make up a large proportion of the rural food stamp recipients. In 2006, children accounted for about onequarter of the rural population, but they made up 40 percent of the rural population that depended on food stamps. Fifty percent of the rural food stamp recipients were adults age 18 to 59 , and 10 percent were 60 and older.

Rural and urban food stamp recipients share several characteristics. They are both more likely than the rest of the population to be children, and they are more likely than others to have low education levels and to be female. Yet, significant differences between these two groups exist. Rural residents who receive food stamps are more likely than their urban counterparts to be non-Hispanic white (61 percent of rural versus 35 percent of urban residents). Urban food stamp recipients are more likely to be non-Hispanic black (33 percent versus 22 percent of rural recipients) or Hispanic (26 percent versus 9 percent). Rural food stamp recipients are also more likely to be married than their urban counterparts ( 34 percent versus 26 percent) and to live in the South (55 percent versus 39 percent).

Researchers find that 35 percent of individuals eligible for the program do not participate. ${ }^{3}$ Frequently cited reasons for nonparticipation include uncertainty about one's eligibility, aversion to reliance on government programs, and the large amounts of time and costs involved in applying for the program. ${ }^{4}$ For rural residents, transportation to the food

TABle 1. Food Stamp Recipients in RuRAL AND URbaN AmericA, 2006

\begin{tabular}{lrrr}
\hline & TOTAL & RURAL & URBAN \\
\hline Total population (in millions) & 293.8 & 46.2 & 245.4 \\
Received food stamps (in millions) & 22.9 & 4.8 & 17.9 \\
Percent receiving food stamps & 7.8 & 10.3 & 7.3 \\
\hline
\end{tabular}

Source: 2006 March CPS

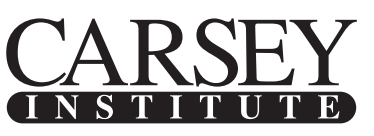

BUILDING KNOWLEDGE FOR Families and Communities IN THE 21ST CENTURY
Huddleston Hall, 73 Main Street, Durham, NH 03824

(603) 862-2821 • www.carseyinstitute.unh.edu

The Carsey Institute Reports on Rural America are supported by the Annie E. Casey Foundation's initiative to strengthen rural families, the Ford Foundation, and the W.K. Kellogg Foundation. 
stamp office may also prove unduly challenging. ${ }^{5}$ Targeted outreach efforts could increase the number of rural Americans benefiting from the food stamp program.

\section{Rural Children More Likely to Receive Free or Reduced Price Lunch}

The National School Lunch Program reaches a large proportion of American children of grade school age (5 to 18 years old). Nationally in 2006, 70 percent of American grade-school children either purchased their lunch from the program or received it for free or at a reduced price (see Table 2). Larger shares of rural (79 percent) than urban children (68 percent) received a school lunch in 2006.

In 2006, 31 percent of America's rural grade-schoolers received a free or reduced price school lunch compared with 25 percent of urban grade-schoolers. Based on their share of the population, rural grade-school children are disproportionately in need of the free or reduced price lunch. Although just 15 percent of grade-school children lived in rural areas in 2006, 19 percent received a free or reduced price lunch.

Across all race and ethnic groups, rural grade-school children are more likely to receive free or reduced price school lunch than their urban counterparts. Nearly three of five rural non-Hispanic black grade-school children received a free or reduced price lunch, while fewer than one-half of urban non-Hispanic black children did. Likewise, larger shares of Hispanic grade-school children (51 percent) in rural areas received a free or reduced price lunch than those living in urban areas (46 percent).

Rural grade-school children living in the South are more likely to receive free or reduced price lunch compared with rural children living in the other regions (41 percent versus approximately 25 percent in the other regions). No such regional variation is evident among urban program recipients.

Although the CPS does not provide data on the Fresh Fruits and Vegetables Program (FFVP), it is likely that this program would have a positive impact on rural children, given it is part of the National School Lunch Program in a limited number of schools. Currently the FFVP operates in 14 states and three Tribal Organizations. ${ }^{6}$ An evaluation of the pilot FFVP component of the Farm Bill showed that most participating schools were very interested in continu-

Table 2. Participation in the National School Lunch Program in Rural and Urban America, 2006

\begin{tabular}{lcrc}
\hline & TOTAL & RURAL & URBAN \\
\hline Children 5 to 18 years (in millions) & 57.5 & 8.9 & 48.3 \\
Received school lunch (in millions) & 40.3 & 7.0 & 33.0 \\
Percent receiving school lunch & 70.0 & 78.7 & 68.4 \\
Received free or reduced price school lunch (in millions) & 14.9 & 2.8 & 12.0 \\
Percent receiving free or reduced price school lunch & 25.9 & 31.4 & 24.9 \\
\hline
\end{tabular}

Source: 2006 March CPS ing the program, and 100 of the 105 schools thought it would be feasible to continue the program beyond the pilot if funding were continued. ${ }^{7}$ Expanding the FFVP nationwide could increase access to fresh fruits and vegetables for millions of grade-school children. Clearly, this program has some support in the Administration's 2007 Farm Bill proposal, which allocates $\$ 500$ million over the next ten years for the purchase of additional fresh fruits and vegetables within the National School Lunch and Breakfast Programs. ${ }^{8}$

\section{Conclusion}

The Food Stamp and the National School Lunch Programs are vital parts of the safety net in rural America, helping a large number of children and others combat hunger and food insecurity. A Farm Bill that strengthens and expands the Food Stamp and Fresh Fruits and Vegetables Programs will help alleviate food insecurity and hunger in rural America and contribute to healthier lives.

\section{Data Used}

Analyses presented in this fact sheet rely on data from the U.S. Census Bureau's 2006 Annual Social and Economic Surveys (ASEC) of the Current Population Surveys (CPS). The CPS provides a nationally representative sample of households and the individuals in those households, and collects demographic, economic, and employment information, as well as participation in selected government assistance programs. Comparisons presented in the text are statistically significant at the 0.05 level.

\section{E N D N O T E S}

${ }^{1}$ Nord, M., M. Andrews, and S. Carlson. 2005. "Household Food Security in the United States, 2004." Economic Research Report, number 11. USDA, Washington, DC.

${ }^{2}$ The term "rural" here refers to persons living outside the officially designated metropolitan areas. "Urban" refers to persons living within metropolitan areas. Metropolitan residence is based on 2003 Office of Management and Budget delineation. The residence of less than 1 percent of Americans was not identified by the Census Bureau to protect their confidentiality, and these individuals are not included in the analysis comparing rural and urban residents.

${ }^{3}$ Wolkwitz, K. 2007. “Trends in Food Stamp Program Participation Rates: 1999 to 2005." Mathematica Policy Research, Inc.

${ }^{4}$ Bartlett, S. and N. Burstein. 2004. "Food Stamp Program Access Study Eligible Non-participants." Report E-FAN-03-013-2, prepared by Abt Associates Inc. under a research contract from the USDA, Economic Research Service.

${ }^{5}$ Molnar, J., P. Duffy, L. Clayton, and C. Bailey. 2001. "Private Food Assistance in a Small Metropolitan Area: Urban Resources and Rural Needs." Journal of Sociology and Social Welfare 28(3):187-209.

${ }^{6}$ USDA. 2007a. "Fresh Fruit and Vegetable Program (FFVP): Quick Facts." USDA, Washington, DC

${ }^{7}$ Buzby, J., J. Guthrie, and L. Kantor. 2003. "Evaluation of the USDA Fruit and Vegetable Pilot Program: Report to Congress." USDA, Food Assistance and Nutrition Research Program, Washington, DC.

${ }^{8}$ USDA. 2007b. "USDA’s 2007 Farm Bill Proposals: Title IV Nutrition Programs." Washington DC. 